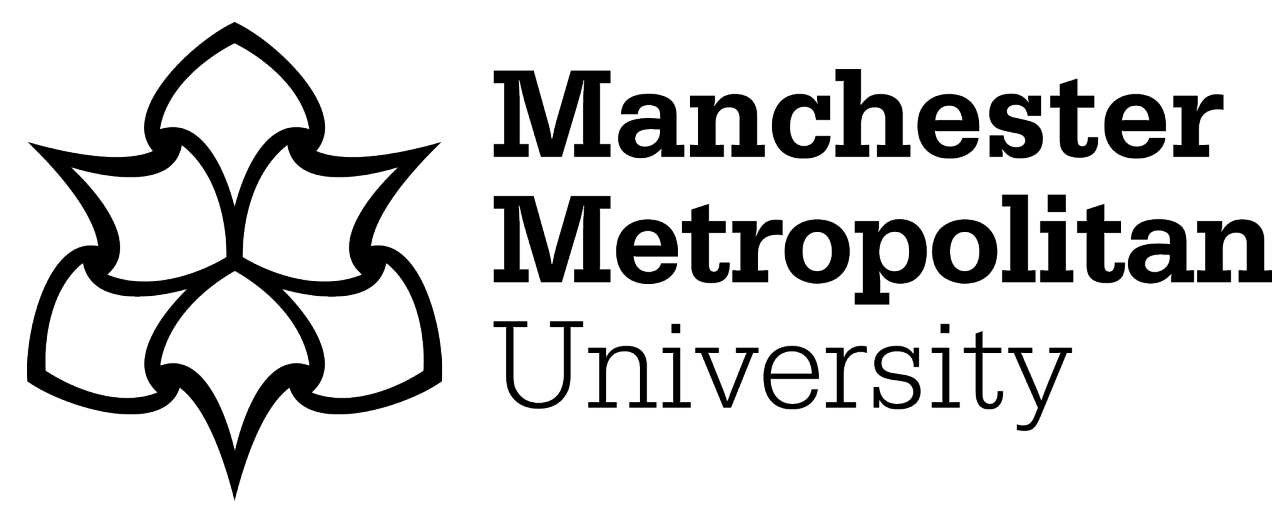

Christie, SM, Lobo, P, Lee, D and Raper, D (2017) Gas Turbine Engine Nonvolatile Particulate Matter Mass Emissions: Correlation with Smoke Number for Conventional and Alternative Fuel Blends. Environmental Science and Technology, 51 (2). pp. 988-996. ISSN 0013-936X

Downloaded from: https://e-space.mmu.ac.uk/617656/

Version: Accepted Version

Publisher: American Chemical Society

DOI: https://doi.org/10.1021/acs.est.6b03766

Please cite the published version 
This document is confidential and is proprietary to the American Chemical Society and its authors. Do not copy or disclose without written permission. If you have received this item in error, notify the sender and delete all copies.

\section{Gas Turbine Engine Non-volatile Particulate Matter mass emissions: Correlation with Smoke number for Conventional and Alternative Fuel Blends}

\begin{tabular}{|r|l|}
\hline Journal: & Environmental Science \& Technology \\
\hline Manuscript ID & es-2016-03766u.R1 \\
\hline Manuscript Type: & Article \\
\hline Date Submitted by the Author: & 03-Nov-2016 \\
\hline Complete List of Authors: & $\begin{array}{l}\text { Christie, Simon; Manchester Metropolitan University, Centre for Air } \\
\text { Transport and the Environment } \\
\text { Lobo, Prem; Missouri University of Science and Technology, Center of } \\
\text { Excellence for Aerospace Particulate Emissions Reduction Research } \\
\text { Lee, David; Manchester Metropolitan University, Department of } \\
\text { Environmental and Geographical Sciences } \\
\text { Raper, David; Manchester Metropolitan University, Envmtl and } \\
\text { Geographical Sciences }\end{array}$ \\
\hline
\end{tabular}


1

$8{ }^{1}$ Centre for Aviation Transport and the Environment, Faculty of Science and Engineering,

15 Keywords: Aviation, gas turbine, smoke number, mass concentration, black carbon, non16 volatile particulate matter, FOA3,

\section{Blends}

* Corresponding author E-mail address: s.christie@mmu.ac.uk 
18 ABSTRACT

19 This study evaluates the relationship between the emissions parameters of smoke number 20 (SN) and mass concentration of non-volatile particulate matter (nvPM) in the exhaust of a gas 21 turbine engine for a conventional Jet A-1 and a number of alternative fuel blends. The data 22 demonstrate the significant impact of fuel composition on the emissions, and highlight the 23 magnitude of the fuel-induced uncertainty for both SN within the Emissions Data Bank, as well as nvPM mass within the new regulatory standard under development. Notwithstanding these substantial differences, the data show correlation between $\mathrm{SN}$ and nvPM mass concentration still adheres to the First Order Approximation (FOA3), and this agreement is maintained over a wide range of fuel compositions. Hence the data support the supposition that the FOA3 is applicable to engines burning both conventional and alternative fuel blends without adaption or modification. The chemical composition of the fuel is shown to impact mass and number concentration as well as geometric mean diameter of the emitted nvPM, however the data do not support assertions that the emissions of black carbon with small mean diameter will result in significant deviations from FOA3.

\section{INTRODUCTION}

35 Emissions from aircraft gas turbine engines include the combustion products carbon dioxide $\left(\mathrm{CO}_{2}\right)$ and water $\left(\mathrm{H}_{2} \mathrm{O}\right)$, combustion by-products: oxides of nitrogen $\left(\mathrm{NO}_{\mathrm{x}}\right)$ and

37 products of incomplete combustion: carbon monoxide (CO), unburned hydrocarbons (UHC) and soot aerosol (or black carbon, BC). Each of these species are produced in different relative proportions and all impact or contribute to climate forcing and degradation of air 40 quality ${ }^{1,2,3,4}$. 
41 The International Civil Aviation Organization (ICAO) sets regulatory standards for NOx, $42 \mathrm{CO}$, UHC and Smoke Number, which are reported for all certified aircraft engine types $43>26.7 \mathrm{kN}$ thrust in the Emissions DataBank ${ }^{5}$ (EDB). Emissions of BC are not currently 44 reported within the ICAO EDB, but may be inferred through the surrogate measurement of 45 Smoke Number (SN) at specific thrust settings that correspond to those used in the Landing and Take-Off (LTO) cycle. SN is an optically based method that quantifies the change in the 47 reflectance of a Whatman \#4 filter paper after sampling a fixed mass of engine exhaust per 48 unit area at a given temperature ${ }^{6}$. The ICAO regulation of SN was originally introduced in 491981 as means to quantify aircraft exhaust plume visibility and to act as a driver to reduce emissions. SN does not provide a characterization of $\mathrm{BC}$ emissions in terms of mass and number concentration, size distribution, or chemical composition, and given its proxy nature, cannot be used to directly determine the environmental impacts of aviation. Currently, there is an initiative within ICAO to replace the SN with a regulatory measurement methodology 54 for non-volatile particulate matter (nvPM) emissions for aircraft engines certified for use in the commercial sector. In the meantime, $\mathrm{SN}$ remains the only measurement whereby $\mathrm{BC}$ emissions can be estimated for environmental assessment activities.

A number of studies have reported the correlation between SN and mass concentration of black carbon $(\mathrm{C}(\mathrm{BC}))$ using a range of different hardware: Champagne ${ }^{7}$ reports a correlation derived from exhaust samples extracted from a combustor rig based on a T56 turboprop engine; Whyte ${ }^{8}$ presented a method to convert between $\mathrm{SN}$ and $\mathrm{C}(\mathrm{BC})$ from a study of 61 kerosene alternative fuels; and Girling et al. ${ }^{9}$ report a correlation from an experimental study 62 using soot generated by a kerosene fuelled smoke generator amongst others ${ }^{10,11}$. A critical 63 inter-comparison of these and other data, which agree to within $10 \%$, was presented by 64 Wayson et al. ${ }^{12}$. These correlations between $\mathrm{SN}$ and $\mathrm{C}(\mathrm{BC})$ form the basis of a method 
66 concentration and/or mass-based emission index of BC emitted from aircraft engines, referred 67 to as the 'First Order Approximation ${ }^{13}$ version 3' (FOA3). The FOA3 is intended for use as a standard method to estimate PM mass-based emissions from certified commercial aircraft engines within the vicinity of airports, and as an important assessment tool, there is a commitment to improve FOA3 as new data become available until such time that the methodology is rendered obsolete by a fully validated database of PM emission indices for the commercial fleet.

73 Nevertheless, there has been criticism of FOA3, not least because of the potential for the SN measurement to be dependent upon the capture efficiency of the filter and thus particle size distribution of the emitted BC. This potential for error was first alluded to by Dodds et al. ${ }^{14}$, followed by Wayson et al. ${ }^{12}$, Sevcenco et al. ${ }^{15}$, and most recently discussed by Stettler et al. ${ }^{16}$, though any suggestion that the $\mathrm{SN}$ underestimates $\mathrm{C}(\mathrm{BC})$ would mainly be applicable to more recent engine technology due to the reduced mean diameter of the emitted $\mathrm{BC}$. However, as will be demonstrated and discussed later, the correlation between $\mathrm{SN}$ and $\mathrm{C}(\mathrm{BC})$ remains a good first order approximation, even when the emitted $\mathrm{BC}$ particles have a mean geometric diameter of the order of $20 \mathrm{~nm}$. estimating the mass concentration of $\mathrm{BC}$ using $\mathrm{SN}$ values may arise when there is the need to interpolate between data points at the four specific LTO thrust settings to determine intermediate values, and also more generally, from the error in the reported SN data itself induced by both measurement uncertainty and the use of non-standardized fuel for certification tests on different engine types. Concerning this latter point, the hydrogen to carbon ratio (H:C) and the aromatic content of the fuel used to produce the $\mathrm{SN}$ data for the specific engine type and in the specific emissions certification test are (mostly) recorded within the EDB. The spectrum of reported values in the EDB legacy data of $1.85-2.00$ for 
$91 \mathrm{H}: \mathrm{C}$ ratio and $11.9 \%-22.5 \%$ for aromatic content, covers a range that extends slightly

92 beyond the current recommended specification for fuel to be used in aircraft engine emission 93 testing of $1.85-1.99$ and $15 \%-23 \%$, respectively ${ }^{17}$. Nevertheless, even the current 'tightened' specification envelope allows for considerable variation in fuel properties, such that the known impacts of fuel composition upon SN are ostensibly not considered. The variation in the fuel properties reported within the ICAO EDB reveal that aromatic content may vary by $\pm 3 \%$ at a given $\mathrm{H}: \mathrm{C}$ ratio, and $\mathrm{H}: \mathrm{C}$ ratio may vary by \pm 0.05 at a given aromatic content. And whilst a decrease in aromatic content is generally associated with an increase in $\mathrm{H}: \mathrm{C}$ ratio, the correlation between these two parameters is generally poor and insufficient to define the fuel. SN's at take-off power have decreased from the 25 - 35 range in early data, to values for newer engine technology that typically occupy the $0-5$ range. However, a $\mathrm{SN}$ of zero is clearly a problem for the application of FOA3 in air quality and climate models as it implies that the mass concentration of $\mathrm{BC}$ is also zero. For these reasons, ICAO has committed to develop a new direct nvPM standard, but with typical engine lifetimes exceeding 20 years, older legacy engines will continue to contribute to overall emission levels and so both SN and FOA3 may not be fully transitioned for some years to come. turbine engine nvPM number and mass-based emissions uses the standard methodology specified in the Society of Automotive Engineers (SAE) Aerospace Information Report (AIR) $6241^{18}$. The development of this standard methodology for engine nvPM emission measurement was born out of the Aircraft Particle Emissions eXperiment (APEX) campaigns and many other similar studies ${ }^{19,20,21,22,23,24,25}$. These studies highlighted the complexity of BC emissions measurement, and in particular the difficulty in obtaining repeatable and reliable 
116 measurement data. The data presented here have been obtained using the AIR6241 compliant

117 system North American Mobile Reference System that has been developed and robustly characterized over several years through international collaboration ${ }^{26}$.

119 The objective of this work was to compare SN measured using a SAE Aerospace Recommended Practice (ARP) $1179 \mathrm{~d}^{6}$ compliant system with the nvPM mass concentration measured using the SAE AIR6241 compliant system for a conventional Jet A-1 and a number of alternative fuel blends. In contrast to earlier FOA3 analysis where the correlation was examined in terms of engine technology applicability, here we analyze the FOA3 correlation from a fuel composition perspective. The gas turbine engine used in this study, a Garrett Honeywell GTCP85-129 auxiliary power unit (APU), is not included within the EDB as its rated output is $<26.7 \mathrm{kN}$. It is however a suitably close analogue to aircraft main engines that provides a good model soot aerosol, and advances the methodologies previously used in the development of the FOA3.

The chemical composition of the test fuels was managed by introducing various blends of Jet A-1 and a Used Cooking Oil derived Hydrotreated Esters and Fatty Acids (UCO-HEFA) kerosene. A complete range of fuels was investigated to allow full characterization of the data aerosol is also present as a co-variable.

137 The significant impact of fuel aromatic content and/or fuel $\mathrm{H}: \mathrm{C}$ ratio on nvPM emissions and measured $\mathrm{SN}$, is highly relevant to both the recommended specification for fuel to be used in aircraft engine certification testing and the downstream effect on accurate emission 
141 potential impact of fuel compositional change becomes considerably more pronounced and 142 pertinent within the context of alternative fuels, and to the projected scale-up of sustainable 143 alternative aviation fuel use (eg. EU Flightpath $2020^{27}$ ), together with future fuel 144 certification, fuel diversification, and long-term fuel security. Sustainable alternative fuels are anticipated to play a sizeable role in decarbonizing the aviation industry, and currently there response function.

are no methods to quantify the much-reduced atmospheric burden of $\mathrm{BC}$ that results from their use $^{28}$. Any future update to FOA3 may need to incorporate a SN-fuel composition

\section{BACKGROUND}

\section{Soot aerosol}

Unfortunately the term 'soot aerosol' is rather imprecise in its definition, and terms such as particulate matter, soot, black carbon, graphitic carbon, refractive carbon and non-volatile particulate matter are often used synonymously. On occasions even the term carbon black is used, even though this is distinct in that it is a manufactured product ${ }^{29}$. Efforts to develop precise nomenclature to distinguish between these terms are on-going, but these are often based on particular measurement techniques or light-absorbing properties ${ }^{30,31,32,33}$ and lack universal acceptance.

In recent years, the term black carbon $(\mathrm{BC})$ has gained widespread usage within the climate and emissions measurement communities, although it is recognized that $\mathrm{BC}$ is in itself a generic term that describes a wide range of carbonaceous combustion derived substances from partly charred residues to highly graphitized $\operatorname{soot}^{34}$. BC particles have highly variable physical properties and chemical compositions that very much depend upon their source ${ }^{35,36}$. Indeed the disparate nature of $\mathrm{BC}$ from different sources is well established and has even been used in source apportionment studies. Physical properties such as size, morphology, 
166 heterogeneity, surface area, isotopic ratio and density are all variable, as is chemical 167 composition with solvent extractable organic matter, and total carbon sometimes being 168 primarily elemental carbon (EC), but more often existing as complex mixtures of EC and 169 organic carbon (OC), with volatile and semi-volatile hydrocarbons, and other non-carbon 170 species such as ionic species, sulphates, moisture and trace metals ${ }^{37,38,39,40}$.

171 Laboratory-generated ultrafine EC particles such as those created in a diffusion flame are 172 yet another distinct form of carbonaceous material. Overall, scientific studies need to clearly 173 distinguish between these highly disparate EC-containing particles with care and precision to 174 forestall the unwarranted extrapolation of properties and the transposition of inappropriate 175 study conclusions from one material to another. Black carbon from one combustion source is 176 not necessarily a model particle that is representative of the characteristics of an entirely 177 different combustion source.

178 The focus of this work is to evaluate the correlation between current and forthcoming 179 regulated measurement techniques using the soot aerosol emitted from a gas turbine engine burning a conventional Jet A-1 and a number of alternative fuel blends. The precise bounds and classification of the emitted soot aerosol is therefore operationally defined by the measurement technique employed. Within this text, the term black carbon is used to define the measurand associated with the measurement of smoke number through SAE ARP1179d, whilst the term non-volatile particulate matter is used to define the measurand associated with the measurement of mass concentration, number concentration and size distribution through SAE AIR6241, although it is recognized that size distribution is not a formal part of this standard. The term soot aerosol is used elsewhere in the broader discussion to represent less defined states.

\section{Impact of fuel chemistry on soot aerosol formation}


Aviation Jet A-1 is a complex cocktail of thousands of different hydrocarbon component molecules, though these molecules are often categorized into four principal groupings: nparaffins, iso-paraffins, cyclo-paraffins and aromatics ${ }^{41}$. The former two groupings of $n$ - and iso-alkanes typically dominate the class composition of all-fit-for-purpose petroleum derived fuels ${ }^{42}$.

Variability in the chemical composition of Jet A-1 (and other kerosene specifications such as Jet A, JP4, JP8, etc.) over both region and time is commonplace. The extent of this variation is largely reflective of variability in the feedstock crude and localized demand for other petrochemical distillation fractions. It is assessed on a regional level within fuel survey data such as Rickard ${ }^{43}$ or the Petroleum Quality Information System ${ }^{44}$ (PQIS). Furthermore, this diversity in the chemical composition of aviation kerosene is set to increase as alternative fuels from a variety of sources enter the market as blend components or substitute fuels.

Perhaps the most notable impact of low aromatic kerosene fuels, including Jet A-1 blended with Fischer-Tropsch (F-T) or Hydro-processed Esters and Fatty Acids (HEFA) alternative fuels, is the very strong reduction in black carbon emissions $45,46,47,48,49,50,51$. For example, the Alternative Aviation Fuel Experiment (AAFEX) study using a CFM56-2C1 engine reported concentrations of $\mathrm{BC}$ at the engine exit nozzle may be reduced by as much as $90 \%$ using $\mathrm{F}-\mathrm{T}$ fuels ${ }^{50}$. These reductions affect the mass concentration, number concentration and size of the emitted BC aerosol ${ }^{46,47,51}$. A detailed evaluation of the impact of small variations in the Jet A1 / HEFA fuel blend ratio on the emission of nvPM is given in Lobo ${ }^{52}$. Evidence that the reduction in soot aerosol occurs due to the lower aromatic content of the fuel is becoming established, and aromatics are attributed as the class of compounds that primarily influence the tendency to form $\mathrm{BC}$ and soot precursors during combustion ${ }^{42,45,53}$. For example, DeWitt $^{45}$ in an investigation of fuel composition, material compatibility and its relation to emission characteristics showed that $\mathrm{BC}$ emissions increase with both increasing fuel 
216 aromatic content and increased aromatic molecular weight when evaluated in a T63 turbo

217 shaft engine. This increase in BC emissions was attributed to an increase in soot precursors.

\section{FOA3: smoke number - mass concentration correlation model}

The FOA3 model endorsed by ICAO, is often used to predict the mass concentration of BC in the exhaust emissions of a gas turbine engine from the surrogate smoke number

222 measurement ${ }^{13}$. Such data is routinely required by atmospheric modelers and for the development of emission inventories.

For an engine with $\mathrm{SN}<30$, the mass concentration of $\mathrm{BC}\left(\mathrm{mg} / \mathrm{m}^{3}\right)$ is predicted from the measured smoke number using the following FOA3 equation ${ }^{12}$ :

$$
\mathrm{C}(\mathrm{BC})=0.0694(\mathrm{SN})^{1.24}
$$

Whereas for $\mathrm{SN}>30$, the mass concentration of $\mathrm{BC}\left(\mathrm{mg} / \mathrm{m}^{3}\right)$ is predicted from the measured smoke number and using the following FOA3 equation ${ }^{12}$ :

$$
\mathrm{C}(\mathrm{BC})=0.0297(\mathrm{SN})^{2}-1.802(\mathrm{SN})+31.94
$$

In both of these equations, $\mathrm{C}(\mathrm{BC})$ is reported at standard temperature $(273.15 \mathrm{~K})$ and pressure $(101.325 \mathrm{kPa})$, and the bounds of uncertainty for the correlation are dominated by the error in the measurement of the $\mathrm{SN}$ as errors in measurement of mass concentration are small in comparison ${ }^{12}$.

\section{EXPERIMENTAL METHOD}

\section{Gas turbine engine $\&$ operating conditions}

The Garrett Honeywell GTCP85-129 gas turbine engine used in this study is often operated as an auxiliary power unit (APU) on Boeing 737 aircraft. APU gas turbine engines offer a good model of aircraft main engine combustion characteristics whilst being considerably more manageable and less costly to operate. 
241 In this work, three APU operating conditions were investigated: No Load (NL), 242 Environmental Control Systems (ECS), and Main Engine Start (MES). These conditions 243 correspond to the normal operating conditions for an APU. For each experimental run the 244 APU was put through a warm up sequence using Jet A-1 before switching to the test fuel 245 without interruption, and then stabilizing at the first condition. The test matrix followed a 246 successive step down in power from MES to ECS to NL condition, which represented 1 test 247 cycle. For each of the fuel blends evaluated, this test cycle was twice sequenced without 248 shutdown. The sequence stepped down in power to minimize possible differences in 249 operating temperature and therefore potential differences in the fuel vaporization rates that 250 $\mathrm{kPa}$, and $61-85 \%$, respectively.

\section{Sampling system and instrumentation}

Page $\mathbf{1 1}$ of $\mathbf{3 2}$ 
266 Two identical and almost collocated single-point probes, one for gaseous emissions and SN 267 measurement, and the second for nvPM emissions measurement were place within $1 / 2$ nozzle 268 diameter of the engine exit plane $(\sim 15 \mathrm{~cm})$.

269 The sample line for gaseous emissions and SN was compliant with the specifications in $270 \mathrm{ICAO}^{17}$ Annex 16 Volume 2 and maintained at a temperature of $160^{\circ} \mathrm{C}$. Gaseous species 271 were determined using a Binos Non-Dispersive Infrared Sensor (CO), a Signal Flame 272 Ionization Detector (UHC), and an Eco Physics Chemi-Luminescence Analyser $\left(\mathrm{NO}_{\mathrm{x}}\right)$, each 273 using appropriate span and zero gases between measurements. The SN was determined in 274 accordance with SAE ARP1179 $\mathrm{d}^{6}$ using a Richard Oliver smoke meter to collect at least 275 three filter samples for each fuel and at each engine condition. The reflectance of the filter 276 samples was determined pre and post sampling using a BOSCH reflectometer. . Reported SN 277 data are the arithmetic mean of measurements from 6 filters $(2$ test cycles $\times 3$ filters at each 278 condition) and uncertainty is conservatively estimated as $\pm 2 \mathrm{SN}$. This estimate of uncertainty 279 is consistent with the measured variability, with due recognition that the accuracy of an 280 individual $\mathrm{SN}$ measurement is considered to be $\pm 3 \mathrm{SN}^{6}$.

281 The nvPM emissions were measured using the AIR6241 compliant North American mobile 282 reference system ${ }^{18,26}$. The probe line used to extract nvPM emissions sample was connected 283 to a 3-way splitter using a $7.5 \mathrm{~m}$ long, $7.9 \mathrm{~mm}$ internal diameter thin-walled stainless steel 284 tubing maintained $160^{\circ} \mathrm{C}$. The nvPM sample was diluted with particle-free nitrogen gas via a 285 Dekati ejector diluter and carried to the measurement suite along a $25 \mathrm{~m}$ long, $7.9 \mathrm{~mm}$ 286 internal diameter, carbon-loaded and electrically grounded PTFE tube maintained at $60^{\circ} \mathrm{C}$ in 287 accordance with SAE AIR6241. The nvPM number-based emissions were measured using an 288 AVL Advanced Particle Counter, while nvPM mass-based emissions measurements were 289 obtained using an Artium Laser Induced Incandescence and an AVL Micro Soot Sensor 290 (MSS). Only the nvPM mass data obtained using the MSS is used in this analysis. The 
291 particle size distributions of the nvPM, which are not specified in AIR6241, were measured 292 using the Cambustion DMS500. The $\mathrm{CO}_{2}$ concentration in the diluted nvPM line was 293 measured using a LiCor NDIR detector. The nvPM emissions data are reported at standard 294 temperature and pressure $(273.15 \mathrm{~K}$ and $101.325 \mathrm{kPa})$, which is equivalent to mass concentration data reported via FOA3. All nvPM emission concentration data was corrected for dilution and thermophoretic loss in the sampling system. Measurement uncertainties in nvPM emissions were calculated using $1 \sigma$ standard deviation of the average data.

\section{Properties of test fuels}

300

The two kerosene fuels used in this study were Jet A-1 and UCO-HEFA. The Jet A-1 was straight-run kerosene obtained from Air BP (Kingsbury, UK), while the UCO-HEFA was provided by SkyNRG (Amsterdam, NL). A GC x GC chemical analysis was used to quantify the paraffinic and aromatic chemical composition of the two fuels, a summary of which is shown in Figure 1. The figure shows the significant difference in the composition of the two fuels: the Jet A-1 contains a substantial fraction of cyclo-paraffins and aromatics, whereas these are much reduced for the UCO-HEFA fuel that is dominated by iso-paraffins.

JET A-1
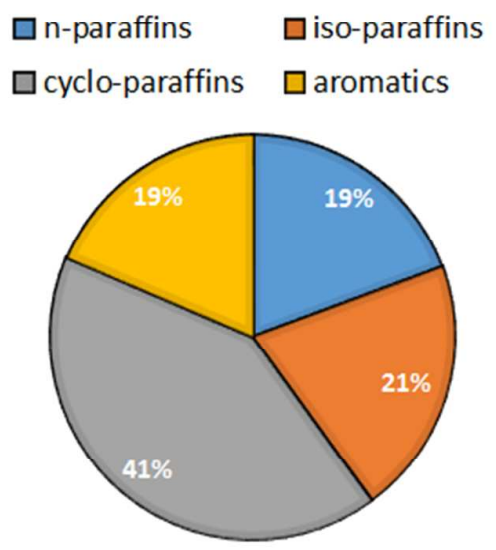

UCO-HEFA
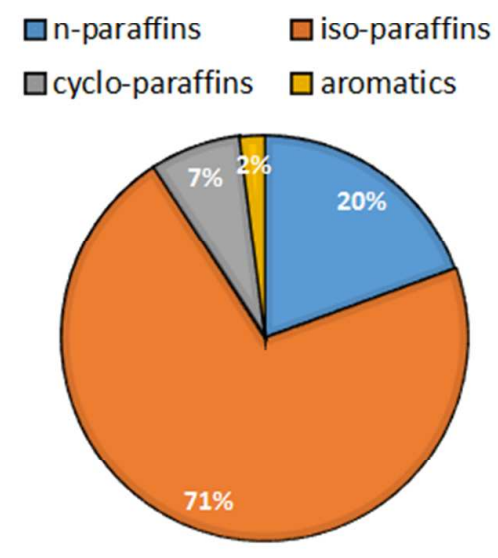
309 Figure 1. Summary of the GC x GC compositional analysis for the Jet A-1 and UCO-HEFA 310 kerosene fuels that were used to formulate the test blends.

312 A number of Jet A-1 / UCO-HEFA kerosene fuel blends were formulated in-house through 313 careful weighing and thorough mixing (blend ratios of $5 \%, 10 \%, 15 \%, 20 \%, 25 \%, 30 \%, 40 \%$, $31450 \%, 60 \%, 70 \%, 75 \%, 80 \%, 85 \%, 90 \%$, and $95 \%$ by mass). The chemical composition of the 315 fuels varied linearly with fuel blend ratio, and test fuel $\mathrm{H}: \mathrm{C}$ ratio varied from 1.89 to 2.14 316 whilst aromatic content correspondingly varied from $19.2 \%$ to $1.8 \%$ by mass. The Jet A-1 317 and UCO-HEFA fuels were fully miscible and the blended fuels were formulated at least 48 318 hours prior to use. It is recognized that several of these blends are outside of current ASTM 319 certification limits for HEFA fuel blends in operational aircraft, however these limits are no longer applicable to the now ground based APU used within this study. Further details of the fuel properties for neat Jet A-1 and UCO-HEFA fuels are given in Lobo et al. ${ }^{52}$.

322 By introducing the hypothetical concept of an aromatic - $\mathrm{H}$ :C ratio space, these fuels can be compared with fuels in the EDB, a world survey of the available JP8 fuels, and the nominal bounds for JP8 jet fuel. The specification for JP8, a military grade kerosene made to more exacting specifications than commercial jet fuel, is used in this context as a proxy, since $\mathrm{H}: \mathrm{C}$ ratio is not defined for checklist Jet A-1. This comparison is shown in Figure 2. 


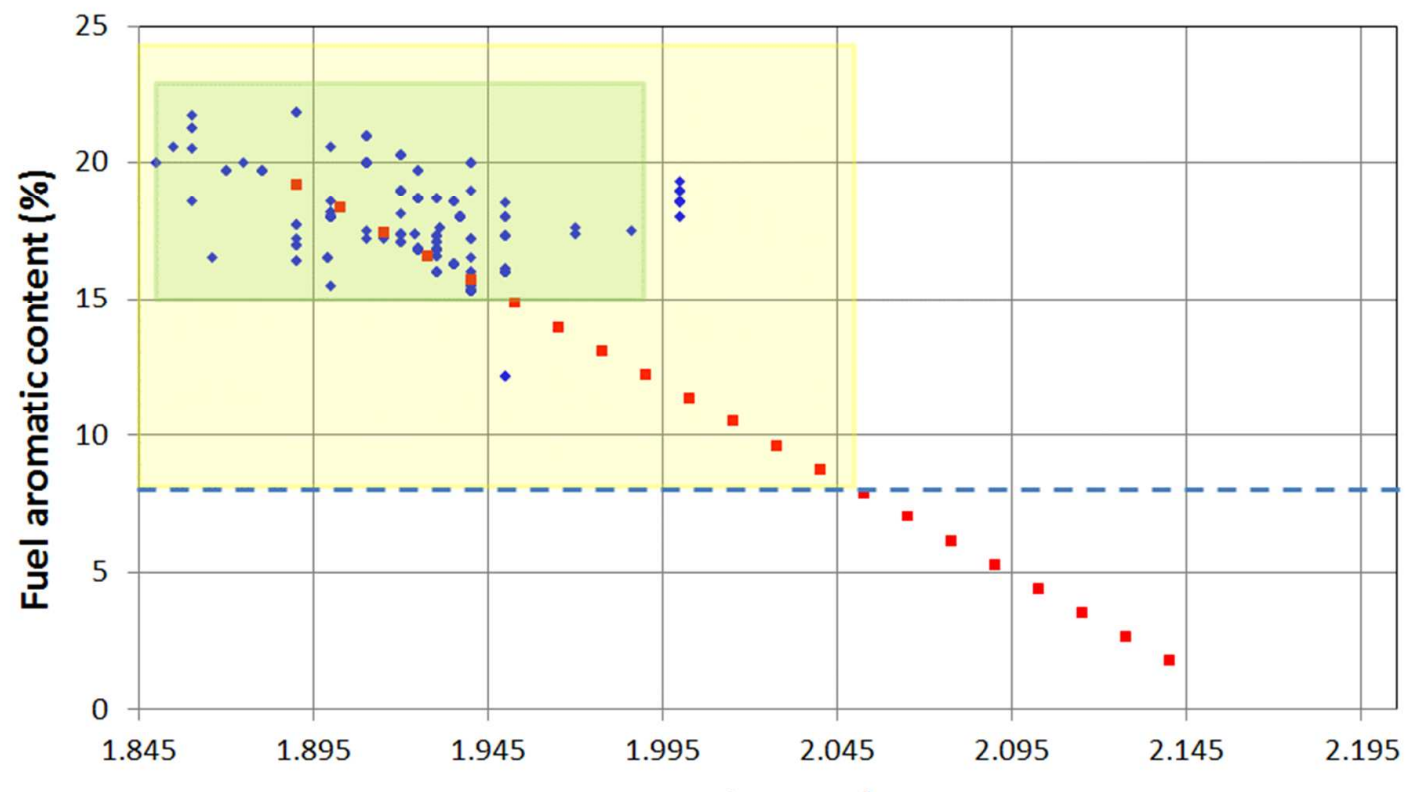

328

329

330

331

332

333

334

335

336

337

338

339

340

341

Fuel H:C ratio

Figure 2. Comparison of aromatic content and $\mathrm{H}: \mathrm{C}$ ratio of different fuels: Blue points: EDB engine certification data; Red points: Experimental fuel blends; Green shaded area: Bounds of ICAO engine test fuel specification ${ }^{17}$; Yellow shaded area: Bounds of PQIS world JP8 2013 survey $^{44}$; Chart area: Nominal bounds for JP8 jet fuel; Blue dashed line: ASTM D7566 minimum aromatic limit ${ }^{54}$.

\section{RESULTS AND DISCUSSION}

\section{Correlation between nvPM mass concentration and SN}

Figure 3 shows the measured nvPM mass concentration, corrected for dilution and thermophoretic $\operatorname{loss}^{18}$, as a function of SN. The different colored data points in the plot indicate the three different engine conditions, and the $\mathrm{BC}$ mass concentration as a function $\mathrm{SN}$ predicted by FOA3 for both $\mathrm{SN}<30$ and $\mathrm{SN}>30$ are also overlaid. 


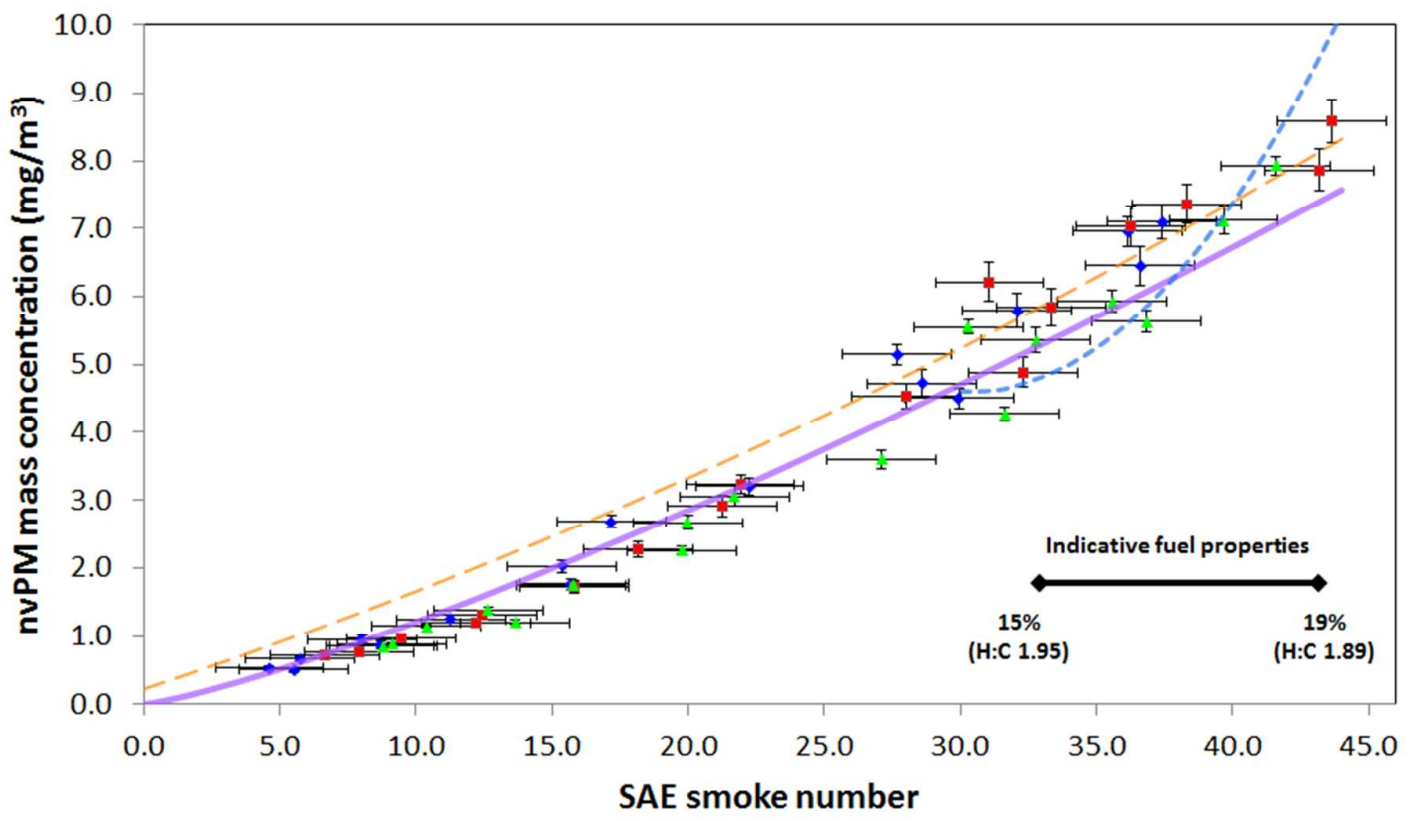

343 Figure 3. nvPM mass concentration as a function of smoke number. Colored data points 344 indicate the three different engine operating conditions: Blue=MES; Red=ECS; Green=NL. 345 The $\mathrm{C}(\mathrm{BC})$ as predicted by FOA3 using $\mathrm{SN}$ data is overlaid: Purple line = FOA Equation 1 346 (nominally applicable for $\mathrm{SN}<30$ ); Dashed blue line = FOA Equation 2 (nominally applicable 347 for $\mathrm{SN}>30$ ); Dashed orange line = upper bound for Equation 1 generated using $+3 \mathrm{SN}$ error 348 [Wayson et al. ${ }^{12}$ ]. An indication of the change in fuel aromatic content (H:C ratio) for ECS operating condition is inset.

The experimental data for the correlation between SN and nvPM mass concentration show close agreement with FOA3, particularly at $\mathrm{SN}<30$. Furthermore this agreement is maintained over a wide range of kerosene compositions, and is largely independent of the engine operating condition. Lines of regression for the datasets representing the three engine conditions are practically coincident (not shown in the figure). The location of specific emissions data on the FOA3 curve is merely dependent upon the chemical properties of the fuel. Data points towards the left in Figure 3 represent measurements from fuel blends with 
358 lower aromatic content and correspondingly greater $\mathrm{H}: \mathrm{C}$ ratio. It is clear that the chemical 359 composition of the kerosene has a significant impact on the tendency to form nvPM. Fuel 360 aromatics have been identified as compounds that primarily influence the tendency to form 361 soot aerosol during combustion ${ }^{45,46}$, although it has long been suggested that fuel hydrogen 362 content may be a more fundamental parameter that is independent of molecular structure ${ }^{58,59}$. 363 The data presented here cannot be used to differentiate between the impact of aromatics and 364 the impact of $\mathrm{H}: \mathrm{C}$ ratio since both vary linearly in the two component fuel blends. 365 Experimental data using multi-component blends or surrogate fuels to adjust these parameters 366 independently is necessary to explore their relative authority. The magnitude of the 367 reductions in $\mathrm{SN}$ and/or nvPM emissions are comparable with data reported elsewhere for 368 other gas turbine engines burning paraffinic fuels $\mathrm{s}^{38,44,45,47,48}$.

369 The nvPM mass concentration $(\mathrm{C}(\mathrm{nvPM}))$ and $\mathrm{BC}$ mass concentration $(\mathrm{C}(\mathrm{BC}))$ as defined 370 by their respective measurement methodologies are not identical, and generally $\mathrm{C}(\mathrm{nvPM}) \geq$ $371 \mathrm{C}(\mathrm{BC})$ since the former encompasses line loss correction factors that are not inherent in latter.

372 The two standards are however closely related and these data support the supposition that $373 \mathrm{C}(\mathrm{nvPM})$ can be estimated from FOA3, but more significantly, that FOA3 can be used with 374 alternative fuel blends of varying chemical composition without adaption or modification.

375 The data indicate that the relation between $\mathrm{C}(\mathrm{nvPM})$ and $\mathrm{SN}$ is foremost represented by 376 FOA3 equation (1), even at $\mathrm{SN}>30$. Using all data points in Figure 3 and a power law fit to 377 be consistent with FOA3 equation (1), the line of regression is given by:

$378 \mathrm{C}(\mathrm{nvPM})=0.048(\mathrm{SN})^{1.35}$

379 Whilst using a constrained range of data points up to $\mathrm{SN}<30$, the line of regression is given 380 by:

$381 \mathrm{C}(\mathrm{nvPM})=0.058(\mathrm{SN})^{1.27}$ 
with the correlation coefficients of $\mathrm{R}^{2}=0.979(\mathrm{n}=51)$ and $\mathrm{R}^{2}=0.965(\mathrm{n}=33)$, respectively (to simplify the representation of data, these lines of regression are not included in Figure 3). Figure 3 also shows a marker to indicate the $15 \%$ - 19\% fuel aromatic range for the ECS engine operating condition (markers for other engine conditions are of comparable magnitude but offset relative to the $\mathrm{SN}$ axis). This marker corresponds to the mid-range and the lower bound for aromatic content in the ICAO specification for fuel to be used for aircraft engine certification testing. For this modest shift in fuel composition, the SN decreased by $30 \%$ and $\mathrm{C}(\mathrm{nvPM})$ decreased by $45 \%$. Hence the fuel-induced uncertainty in EDB SN or C(nvPM) derived through FOA3 is potentially twice this number, when considered in respect of the limits of fuel used for engine certification testing ${ }^{17}$ and typical commercial fuel variability ${ }^{43}$. SN data for a particular engine in the EDB is strictly only correct for the stated certification test fuel and will increase or decrease in magnitude for fuel of different chemical composition.

The data suggest that for engines with relatively large reported SNs the fuel-induced uncertainty could be significant and markedly greater than the nominal \pm 3 SN uncertainty associated with the measurement of $\mathrm{SN}$, whilst for engines with relatively small reported SNs the fuel-induced uncertainty will be captured within this same \pm 3 SN measurement uncertainty. The proportional reduction in nvPM mass are consistent with data reported by Brem et al. ${ }^{55}$ in a study evaluating the impact of fuel aromatic content on nvPM emissions from an in-production gas turbine engine.

\section{nvPM number concentration and size distribution}

Figure 4 shows the measured nvPM number concentration corrected for dilution and thermophoretic $\operatorname{loss}^{18}$ as a function of the measured SN. Measurement uncertainties are as 
406 previously described, and similarly the different colored data points in the plot indicate the 407 three different engine conditions.

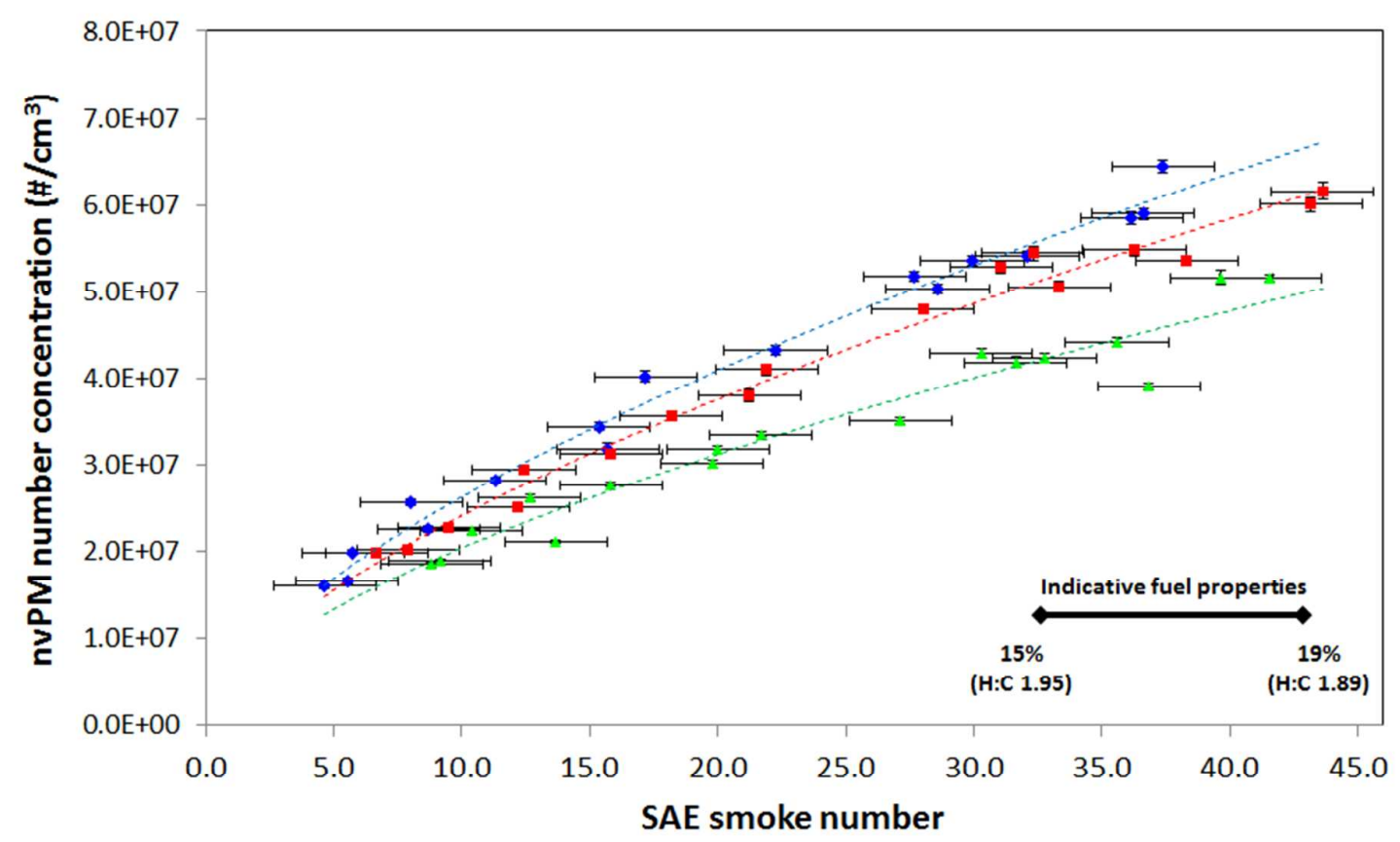

408

409

410

411

412

413

414

415

416

417

418

419

420

421

Figure 4. nvPM number concentration as a function of smoke number. Colored data points indicate the three different engine operating conditions: Blue=MES; Red=ECS; Green=NL. An indication of the change in fuel aromatic content ( $\mathrm{H}: \mathrm{C}$ ratio) for ECS operating condition is inset.

Data points towards the left in Figure 4 represent measurements from kerosene fuel blends of lower aromatic content and show a progressive reduction in the nvPM number concentration. In this case there is some distinction between lines of regression for the three datasets (shown in the figure) indicating that the relation between nvPM number concentration and SN may be dependent upon the engine operating condition.

Figure 4 also shows a marker to indicate the 15\% - 19\% fuel aromatic range for the ECS engine operating condition corresponding to the mid-range and the lower bound for aromatic content in the ICAO specification for fuel to be used in aircraft engine certification testing. 
422 For this shift in fuel composition, SN decreased by $30 \%$ and the nvPM number concentration 423 decreased by $22 \%$. This would suggest that nvPM number concentration is also a strong 424 function of fuel composition, an observation that is consistent with data reported 425 elsewhere ${ }^{52,55}$.

426 The nvPM size distribution parameters of geometric mean diameter (GMD) and geometric 427 standard deviation (GSD) for the fuel blends tested at each of the three APU operating 428 conditions are shown in Figure 5. The nvPM exhibited a characteristic lognormal size 429 distribution, which narrows and shifts the geometric mean diameter to smaller sizes as the 430 aromatic content of the fuel blend is decreased (correspondingly increased $\mathrm{H}$ :C ratio). For a 431 given fuel, the succession of nvPM GMD tracked the sequence NL>ECS $>$ MES. Overall the 432 GMD varied from a minimum of $22 \mathrm{~nm}$ for $1.8 \%$ aromatic fuel in the MES engine condition 433 to $42 \mathrm{~nm}$ for $19.2 \%$ aromatic fuel in the NL engine condition. The corresponding GSD ranged 434 from 1.58 to 1.79 . Hence on the microscopic scale, the fuel-induced reduction in the mass of 435 emitted nvPM corresponds to the emission of fewer and smaller units of particulate matter. 436 These data are consistent with those reported for other gas turbine engines burning 437 conventional and alternative fuels ${ }^{21,26,47,49,50}$. 

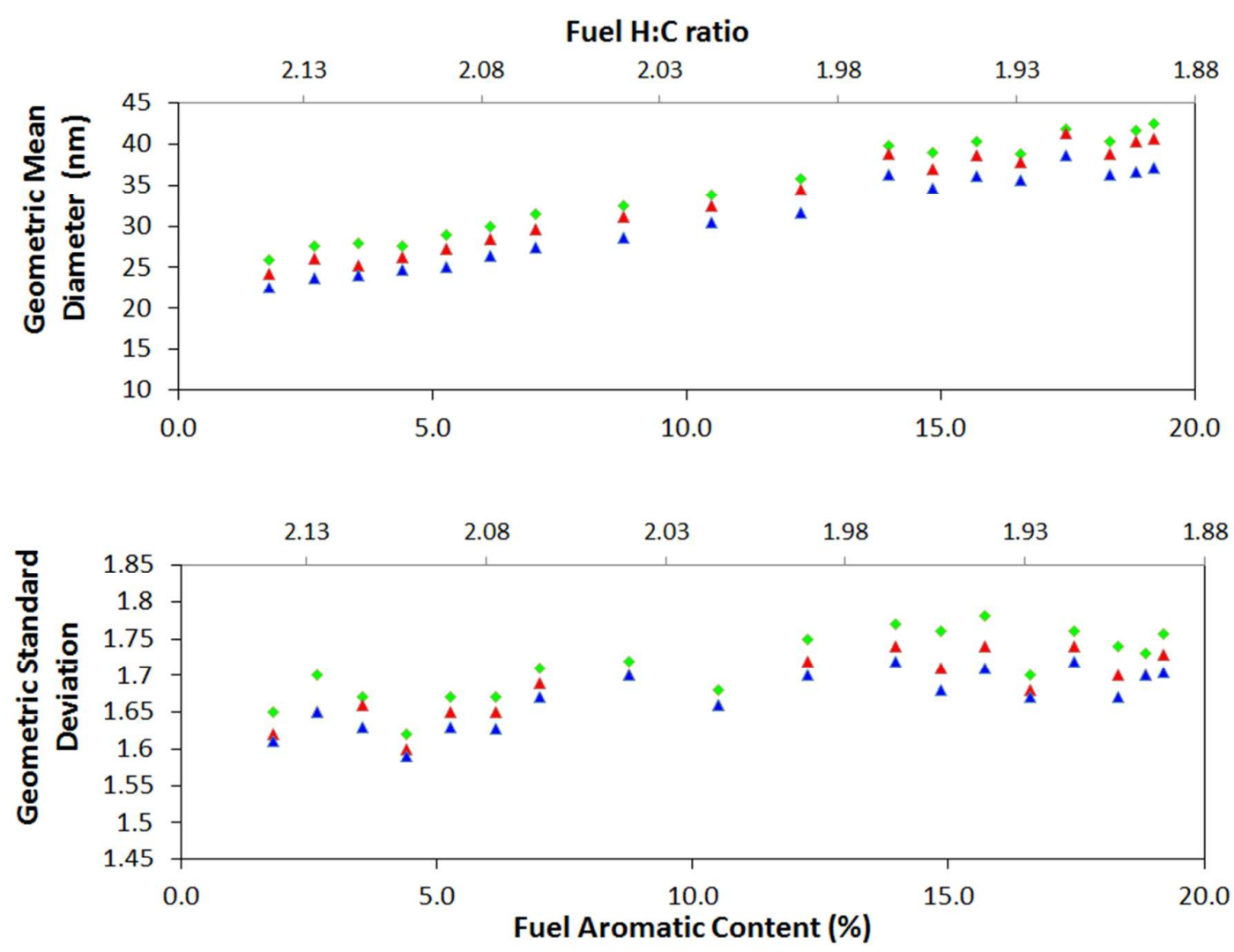

439

440

441

442

443

444

445

446

447

448

449

450

451

452

Figure 5. Geometric mean diameter and geometric standard deviation for nvPM emission from selected fuel blends. Colored data points indicate the three different engine operating conditions: Blue=MES; Red=ECS; Green=NL. In both cases the upper secondary axis shows the corresponding fuel $\mathrm{H}: \mathrm{C}$ ratio.

When these nvPM GMD data are considered in relation to the C(nvPM) in Figure 3, it is evident that the small nvPM with GMD $\sim 22 \mathrm{~nm}$ that are characteristic of modern aircraft engine emissions, do not result in significant deviations in the FOA3 estimation of mass concentration. Previously Stettler et al. ${ }^{16}$ published data that appears to show that the relation between $\mathrm{SN}$ and $\mathrm{C}(\mathrm{nvPM})$ deviates significantly from FOA3 for nvPM with a GMD of the order of $20 \mathrm{~nm}$, with deviations of up to a factor 3 . The data presented here do not support this finding. The data presented by Stettler et al. ${ }^{16}$ do not represent a fair comparison with the FOA3 method in three principal ways. Firstly, the applied methodology did not have a direct 
453 measurement of nvPM mass concentration, but rather estimated it from size distribution and 454 effective density measurements. In the current work, we directly measure nvPM mass. 455 Secondly, Stettler's experiments were based on laboratory measurements of propane 456 diffusion flame combustion, and the black carbon generated from a propane burner is not a 457 model particle that is representative of the soot aerosol produced by a gas turbine engine. 458 Propane burners produce black carbon via a different mechanistic route (as chemically 459 dissimilar) that result in high EC fraction particulate matter with different physical and 460 chemical properties. This assertion is supported by experimental data from Durdina et al. ${ }^{56}$. 461 Thirdly, the SN measurement methodology employed by Stettler was not comparable with the 462 methodology that has been used to populate the data in the ICAO EDB. The use of a catalytic 463 stripper to remove the semi-volatile OC from the line is not compliant with SAE ARP1179 $\mathrm{d}^{6}$ 464 and will result in a relatively 'clean' source of soot aerosol to be impingent upon the SN 465 filter. The impact of volatiles to the measurement of SN was demonstrated by Rye et $\mathrm{al}^{60}$.

466 The data in Stettler et al. ${ }^{16}$ do demonstrate that a 'clean' black carbon from a propane 467 burner is captured with a progressively decreasing efficiency as the geometric mean diameter 468 is reduced. However, the extrapolation that these data are applicable to the emission of nvPM 469 from an aircraft gas turbine engine cannot be justified because of the differences in both the 470 modeled source for $\mathrm{BC} / \mathrm{nvPM}$ and the measurement methodologies employed. This is 471 important since Stettler et al. ${ }^{16}$ claim that the FOA3 significantly underestimates aircraft 472 emissions of $\mathrm{BC}$ by a factor of $2.5-3$ for $\mathrm{SN} \leq 15$, and consequentially, propose a factor $\sim 3$ 473 upwards revision of aircraft $\mathrm{BC}$ radiative forcing which would make it equivalent to $\sim 1 / 3$ of 474 the aviation $\mathrm{CO}_{2}$ radiative forcing ${ }^{57}$. On the basis of the measurements presented here and 475 critique of the Stettler et $\mathrm{al}^{16}$ methodology, such conclusions and extrapolations cannot be 476 supported. 
477 Significantly, this work develops a comparative framework between current and future 478 regulatory standards for the measurement of soot aerosol from a gas turbine that incorporates 479 the quantitatively distinct emission from the combustion of alternative fuels, and places these 480 within the ICAO endorsed and widely accepted FOA3 methodology. With typical engine 481 lifetimes exceeding 20 years, older legacy engines will continue to contribute to overall 482 emission levels and so both $\mathrm{SN}$ as a surrogate measurement of $\mathrm{BC}$, and FOA3 as a vital 483 assessment tool, may not be fully transitioned for some years to come. The importance of fuel 484 composition and the impact of its attendant variability may be particularly acute in the 485 application of EDB data to air quality modeling and the development of emission inventories. 486

AUTHOR INFORMATION

Corresponding author *E-mail: s.christie@mmu.ac.uk ACKNOWLEDGEMENTS

This work was supported through a combination of agencies: We would like to thank the 492 European Union's Seventh Framework Programme under grant agreement No. 308807 493 (ITAKA), and the UK Government Department for Transport. Any opinions, findings, and 494 conclusions or recommendations expressed in this paper are those of the authors and do not 495 necessarily reflect the views of the sponsors. 
498 BC, Black Carbon; C(BC), Concentration of Black Carbon; C(nvPM), Concentration of 499 non-volatile Particulate Matter; EDB, Emissions Data Bank; FOA3, First Order 500 Approximation (version 3); GMD, Geometric Mean Diameter; GSD, Geometric Standard 501 Deviation; ICAO, International Civil Aviation Organization; LTO, Landing and Take Off; 502 nvPM, non-volatile Particulate Matter; SN, Smoke Number; UCO-HEFA, Used Cooking Oil 503 derived Hydrotreated Esters and Fatty Acids.

504

505

\section{REFERENCES}

(1) Lee, D.S.; Fahey, D.W.; Forster, P.M.; Newton, P.J.; Wit, R.C.N.; Lim, L.L.; Owen, B.; 507 Sausen, R. Aviation and global climate change in the 21 st century. Atmos. Environ. 2009, 43 508 (22), 3520-3537.

(2) Lee, D.S.; Pitari, G.; Grewe, V.; Gierens, K.; Penner, J.E.; Petzold, A.; Prather, M.J.; Schumann, U.; Bais, A.; Berntsen, T.; Iachetti, D.; Lim, L.L.; Sausen, R. Transport Impacts on Atmosphere and Climate: Aviation. Atmos. Environ. 2010, 44 (37), 4678-4734.

(3) Stettler, M.E.; Eastham, S; Barrett, S.R.H. Air quality and public health impacts of UK airports. Part I: Emissions. Atmos. Environ. 2011, 45 (31): 5415-5424.

(4) Yim, S.H.L.; Lee, G.L.; Lee, I.H.; Allroggen, F.; Ashok, A.; Caiazzo, F.; Eastham, S.D.; Malina, R.; Barrett, S.R.H. Global, regional and local health impacts of civil aviation 516 emissions. Environ. Res. Lett. 2015, 10, 034001. 
519 (6) Aircraft Gas Turbine Engine Exhaust Smoke Measurement. Aerospace Recommended 520 Practice 1179d. Society of Automotive Engineers International (SAE). 2011.

521 (7) Champagne, D.L. Standard Measurement of Aircraft Gas Turbine Engine Exhaust 522 Smoke. ASME 71-GT-88. American Society of Mechanical Engineers, New York. 1971, 152311.

524 (8) Whyte, R. B. Alternative Jet Fuels. AGARD Advisory Report no. 181, Vol. 2. National 525 Research Council, Ottawa, Canada. 1982.

526 (9) Girling, S.P.; Hurley, C.D.; Mitchell, J.P.; Nichols, A.L. Development and 527 Characterization of a Smoke Generator for the Calibration of Aerosol Emissions from Gas 528 Turbine Engines. Aerosol Sci. Technol. 1990, 13, 8-19.

(10) Hurley, C. D. Smoke Measurements Inside a Gas Turbine Combustor. AIAA, SAE, ASME and ASEE 29th Joint Propulsion Conference. AIAA, Monterey, CA. 1993, 1-9.

(11) Whitefield, P.D.; Hagen, D.E.; Siple, G.; Pherson, J. Estimation of Particulate 532 533 Emission Indexes as a Function of Size for the LTO Cycle for Commercial Jet Engines. Proc. Air \& Waste Management Association Annual Meeting. Pittsburgh, PA. 2001.

534

(12) Wayson, R.; Fleming, G.; Iovinelli, R. Methodology to Estimate Particulate Matter 535 536 Emissions from Certified Commercial Aircraft Engines. J. Air Waste Manage. Assoc. 2009, $59(1), 91-100$.

537 (13) Airport Air Quality Guidance Manual. Doc 9889. International Civil Aviation 538 Organization (ICAO), Montreal, Canada. 2011.

539 (14) Dodds, W.J.; Peters, J.E.; Colket, M.B.I.; Mellor, A.M. Preliminary Study of Smoke 540 Formed in the Combustion of Various Jet Fuels. J. Energy. 1977, 1 (2), 115-120. 
541 (15) Sevcenco, Y.A.; Bowen, P.J.; Johnson, M.P.; Hilton, M.; Welch, M.; Miller, M.N.

542 Mass and size distribution measurement of particulates from a gas turbine combustor using 543 modern mobility analyzer and particle sizer. 45th AIAA/ASME/SAE/ASEE Joint Propulsion 544 Conference \& Exhibit. Denver, Colorado. AIAA 2009e4827. 2009.

545 (16) Stettler, E.J.; Swanson, J.J.; Barret, S.R.H.; Boles, A.M. Updated correlation between 546 aircraft smoke number and black carbon concentration. Aerosol Sci. Technol. 2013, 47, 1205 5471214.

548 (17) ICAO Annex 16 Environmental Protection, Volume II. Third edition. Appendix 4. 5492008.

550 (18) SAE Aerospace Information Report 6241 (AIR6241). Procedure for the Continuous 551 Sampling and Measurement of Non-Volatile Particle Emissions from Aircraft Turbine 552 Engines. SAE International, Warrendale, PA. 2013.

553 (19) Lobo, P.; Hagen, D.E.; Whitefield, P.D.; Alofs, D.J. Physical Characterization of 554 Aerosol Emissions from a Commercial Gas Turbine Engine. J. Propul. Power. 2007, 23, 919555929.

556 (20) Timko, M.T.; Onasch, T. B.; Northway, M.J.; Jayne, J.T.; Canagaratna, M.R.; 557 Herndon, S.C.; Wood, E.C.; Miake-Lye, R.C.; Knighton, W.B. 2010. Gas Turbine Engine 558 Emissions-Part II: Chemical Properties of Particulate Matter. J. Eng. Gas Turbines Power. 559 2010, 132, (6) 061505.

560 (21) Lobo, P.; Hagen, D.E.; Whitefield, P.D.; Raper, D. PM Emissions Measurements of 561 In-Service Commercial Aircraft Engines during the Delta-Atlanta Hartsfield Study. Atmos. 562 Environ. 2015, 104, 237-245. 
563

564

565

566

567

568

569

570

571

572

573

574

575

576

577

578

579

580

581

582

583

584

585

(22) Kinsey, J.S.; Dong, Y.; Williams, D.C.; Logan, R. 2010. Physical characterization of the fine particle emissions from commercial aircraft engines during the Aircraft Particle Emissions eXperiment (APEX) 1-3. Atmos. Environ. 2010, 44, 2147-2156.

(23) Anderson, B.E.; Beyersdorf, A.J.; Hudgins, C.H.; Plant, J.V.; Thornhill, K.L.; Winstead, E.L.; Ziemba, L.D.; Howard, R.; Corporan, E.; Miake-Lye, R.C.; Herndon, S.C.; Timko, M.; Wood, E.; Dodds, W.; Whitefield, P.; Hagen, D.; Lobo, P.; Knighton, W.B.; Bulzan, D.; Tacina, K.; Wey, C.; Vander Wal, R.; Bhargava, A.; Kinsey, J.; Liscinsky, D.S. Alternative Aviation Fuel Experiment (AAFEX). NASA. TM-2011-217059, Hanover, MD. 2011.

(24) Petzold, A.; Marsh, R.; Johnson, M.; Miller, M.; Sevcenco, Y.; Delhaye, D.; Ibrahim, A.; Williams, P.; Bauer, H.; Crayford, A.; Bachalo, W.D.; Raper, D. Evaluation of methods for measuring particulate matter emissions from gas turbines. Environ. Sci. Technol. 2011, $45,3562-3568$.

(25) Marsh, R.; Crayford, A.; Petzold, A.; Johnson, M.; Williams, P.; Ibrahim, A.; Kay, P.; Morris, S.; Delhaye, D.; Lottin, D.; Vancassel, X.; Raper, D.; Christie, S.; Bennett, M.; Miller, M.; Sevcenco, Y.; Rojo, C.; Bowen, P. Studying, sampling and measurement of aircraft particulate emissions II (SAMPLE II): Final Report. 2010, EASA.2009.OP.18.

(26) Lobo, P.; Durdina, L.; Smallwood, G.J.; Rindlisbacher, T.; Siegerist, F.; Black, E.A.; Yu, Z.; Mensah, A.A.; Hagen, D.E.; Miake-Lye, R.C.; Thomson, K.A.; Brem, B.T.; Corbin, J.C..; Abegglen, M.; Sierau, B.; Whitefield, P.D.; Wang, J. Measurement of Aircraft Engine Non-volatile PM Emissions: Results from the Aviation - Particle Regulatory Instrument Demonstration Experiment (A-PRIDE) 4 Campaign. Aerosol Sci. Technol. 2015, 49, 472484.

Page $\mathbf{2 7}$ of $\mathbf{3 2}$ 
586 (27) Flightpath 2050, Europe's Vision for Aviation. European Union, Belgium. 2011, 587 ISBN 978-92-79-19724-6.

588 (28) Speth, R.L.; Rojo, C.; Malina, R.; Barrett S.R.H. Black carbon emissions reductions 589 from combustion of alternative jet fuels. Atmos. Environ. 2015, 105, 37-42.

590 (29) Long, C.M.; Nascarella, M.A.; Valberg, P.A. Carbon black vs. black carbon and other 591 airborne materials containing elemental carbon: Physical and chemical distinctions. Environ. 592 Poll. 2013, 181, 271-286.

(30) Janssen, N.A.H.; Gerlofs-Nijland, M.E.; Lanki, T.; Salonen, R.O.; Cassee, F.R.; Hoek, 594 G.; Fischer, P.; van Bree Brunekreef, B.; Krzyzanowski, M. Joint World Health Organization 595 Convention Task Force on Health Aspects of Air Pollution Health Effects of Black Carbon. 596 World Health Organization, Regional Office for Europe, Copenhagen, Denmark. 2012.

(31) Andreae, M.O.; Gelencsér, A.; Black carbon or brown carbon? The nature of light598 absorbing carbonaceous aerosols. Atmos. Chem. Phys. 2006, 6, 3419 - 3463.

(32) Petzold, A.; Ogren, J.A.; Fiebig, M.; Laj, P.; Li, S.M.; Baltensperger, U.; Holzer-Popp, 600 T.; Kinne, S.; Pappalardo, G.; Sugimoto, N.; Wehrli, C.; Wiedensohler, A.; Zhang, X.Y. Recommendations for reporting "black carbon” measurements. Atmos. Chem. Phys. 2013, 13, $8365-8379$.

(33) Lack, D.A.; Moosmüller, H.; McMeeking, G.R.; Chakrabarty, R.K.; Baumgardner, D.; Characterizing elemental, equivalent black, and refractory black carbon aerosol particles: a 605 review of techniques, their limitations and uncertainties. Analytical bioanalytical chem. 2014, 606 406, 99-122.

(34) Shrestha, G.; Traina, S.; Swanston, C. Black carbon's properties and role in the 608 environment: a comprehensive review. Sustainability. 2010, 2, 294-320. 
609 (35) Fernandes, M.B.; Skjemstad, J.O.; Johnson, B.B.; Wells, J.D.; Brooks, P. 610 Characterization of carbonaceous combustion residues. I. Morphological, elemental and 611 spectroscopic features. Chemosphere. 2003, 51, 785-795.

612 (36) Fernandes, M.B.; Brooks, P.; Characterization of carbonaceous combustion residues: 613 II. Non-polar organic compounds. Chemosphere. 2003, 53, 447-458.

(37) Matuschek, G.; Karg, E.; Schroppel, A.; Schulz, H.; Schmid, O. Chemical investigation of eight different types of carbonaceous particles using thermoanalytical techniques. Environ. Sci. Technol. 2007, 41, 8406-8411.

(38) Kocbach, A.; Li, Y.; Yttri, K.E.; Cassee, F.R.; Schwarze, P.E.; Namork, E. Physicochemical characterisation of combustion particles from vehicle exhaust and residential wood smoke. Part. Fibre Toxicol. 2006, 3, 1-10.

(39) Report to Congress on Black Carbon. Office of Air Quality Planning and Standards,

Office of Atmospheric Programs, Office of Radiation and Indoor Air, Office of Research and 622 Development, Office of Transportation and Air Quality, US Environmental Protection 623 Agency (US EPA). Washington, DC. EPA-450/R-12-001. 2012.

(40) Huang, L.; Brook, J.R.; Zhang, W.; Li, S.M.; Graham, L.; Ernst, D.; Chivulescu, A.;

$625 \mathrm{Lu}, \mathrm{G}$. Stable isotope measurement of carbon (OC/EC) in airborne particulate: A new 626 dimension for source characterisation and apportionment. Atmos. Environ. 2006, 40, 26906272705.

(41) Shafer, L.M.; Striebich, R.C.; Gomach, J.; Edwards, T. Chemical Class Composition 629 of Commercial Jet Fuels and Other Specialty Kerosene Fuels. 14th AIAA/AHI Space Planes 630 and Hypersonic Systems and Technologies Conference. AIAA Paper 2006-7972. 2006. 
631 (42) Dryer, F.L. Chemical kinetic and combustion characteristics of transportation fuels. 632 Proc. Combust. Inst. 2015, 35, 117-144.

633 (43) Rickard, G. The quality of aviation fuel available in the United Kingdom annual 634 survey 2007. Energy Institute. Qinetiq/08/01656. 2008.

(44) PQIS 2013 annual report: Petroleum quality information system. US defence logistics 636 agency. 2013.

(45) DeWitt, M.J.; Corporan, E.; Graham, J.; Minus, D. Effects of aromatic type and concentration in Fischer-Tropsch fuel on emissions production and material compatibility. 639 Energy \& Fuel. 2008, 22, 2411-2418.

(46) Timko, M.T.; Yu, Z.; Onasch, T.B.; Wong, H.-W.; Miake-Lye, R.C.; Beyersdorf, A.J.; Anderson, B.E.; Thornhill, K L.; Winstead, E.L.; Corporan, E.; DeWitt, M.J.; Klingshirn, C.D.; Wey, C.; Tacina, K.; Liscinsky, D.S.; Howard, R.; Bhargava, A. Particulate Emissions of Gas Turbine Engine Combustion of a Fischer-Tropsch Synthetic Fuel. Energy Fuels. 2010, 24, 5883-5896.

(47) Lobo, P.; Hagen, D.E.; Whitefield, P.D. Comparison of PM emissions from a Commercial Jet Engine burning Conventional, Biomass, and Fischer-Tropsch Fuels, Environ. 647 Sci. Technol. 2011, 45, 10744-10749.

(48) Lobo, P.; Rye, L.; Williams, P.I.; Christie, S.; Uryga-Bugajska, I.; Wilson, C.W.; 649 Hagen, D.E.; Whitefield, P.D.; Blakey, S.; Coe, H.; Raper, D.; Pourkashanian, M. Impact of 650 Alternative Fuels on Emissions Characteristics of a Gas Turbine Engine - Part 1: Gaseous and 651 Particulate Matter Emissions. Environ. Sci. Technol. 2012, 46, 10805-10811.

(49) Cain, J.; DeWitt, M. J.; Blunck, D.; Corporan, E.; Striebich, R.; Anneken, D.; 653 Klingshirn, C.; Roquemore, W. M.; Vander Wal, R. Characterization of Gaseous and 
654 Particulate Emissions From a Turboshaft Engine Burning Conventional, Alternative, and 655 Surrogate Fuels. Energy Fuels. 2013, 27, 2290-2302.

656 (50) Beyersdorf, A.J.; Timko, M.T.; Ziemba, L.D.; Bulzan, D.; Corporan, E.; Herndon, 657 S.C.; Howard, R.; Miake-Lye, R.; Thornhill, K.L.; Winstead, E.; Wey, C.; Yu, Z.; Anderson, 658 B.E. Reductions in aircraft particulate emissions due to the use of Fischer-Tropsch fuels. 659 Atmos. Chem. Phys. 2014, 14, 11-23.

660 (51) Corporan, E.; Edwards, T.; Shafer, L.; DeWitt, M.J.; Klingshirn, C.; Zabarnick, S.; 661 West, Z.; Striebich, R.; Graham, J.; Klein, J.; Chemical, Thermal Stability, Seal Swell, and 662 Emissions Studies of Alternative Jet Fuels. Energy Fuels. 2011. 25, 955-966.

663 (52) Lobo, P.; Christie, S.; Kandelwal, B.; Blakey, S.; Raper, D. Evaluation of non-volatile 664 PM Emissions Characteristics of an Aircraft Gas Turbine Engine with varying Alternative Jet 665 Fuel Blend Ratios. Energy \& Fuel. 2015, 29, 7705-7711.

(53) Christie, S.; Raper, D.; Lee, D.S.; Williams, P.I.; Rye, L.; Blakey, S.; Wilson, C.W.; 667 Lobo, P.; Hagen, D.; Whitefield, P. Polycyclic Aromatic Hydrocarbon Emissions from the 668 Combustion of Alternative Fuels in a Gas Turbine Engine. Environ. Sci. Technol. 2012, 46, $669 \quad 6393-6400$.

670 (54) Standard Specification for Aviation Turbine Fuel Containing Synthesized 671 Hydrocarbons; ASTM D7566; ASTM International. West Conshohocken, PA.

672 (55) Brem, B.; Durdina, L.; Siegerist, F.; Beyerle, P.; Bruderer, K.; Rindlisbacher, T.; 673 Rocci Denis, S.; Andac, G.; Joseph Zelina, J.; Penanhoat, O.; Wang, J.; Effects of fuel 674 aromatic content on non-volatile particulate emissions of an in-production aircraft gas 675 turbine. Environ. Sci Tech. 2015, 49, 13149-13157. 
676 (56) Durdina, L., Lobo, P., Trueblood, M.B., Black, E.A., Achterberg, S., Hagen, D.E., 677 Brem, B.T., Wang, J., Response of Real-Time Black Carbon Mass Instruments to Mini678 CAST Soot. Aerosol Sci. Technol. 2016, 50, 906-918.

679 (57) Stettler, E.J.; Boies, A.M.; Petzold, A.; Barret, S.R.H. Global civil aviation black 680 carbon emissions. Environ. Sci. Tech. 2013, 47, 10397 - 10404.

681 (58) Moses, C.A.; Callahan, T.J.; Cuellar, J.P.; Dodge, L.G.; Likos, W.E.; Naegeli, D.W.; 682 Valtierra, M.L. An Alternate Test Procedure to Qualify Fuels for Navy Aircraft: Phase II. 683 Naval Air Propulsion Center. Trenton, NJ. Report No. NAPC-PE-145C. 1984.

684 (59) Bowden, T.T.; Pearson, J.H.; Wetton, R.J. The Influence of Fuel Hydrogen Content 685 Upon Soot Formation in a Model Gas Turbine Combustor. J. Eng. Gas Turbines Power. $6861984,106,789-794$.

(60) Rye, L.; Lobo, P.; Williams, P.I.; Uryga-Bugajska, I.; Christie, S.; Wilson, C.W.; 688 Hagen, D.; Whitefield, P.; Blakey, S.; Coe, H.; Raper, D.; Pourkashaniand, M. Inadequacy of 689 Optical Smoke Measurements for Characterisation of Non-Light Absorbing Particulate 690 Matter Emissions from Gas Turbine Engines. Combustion Sci. Tech. 2012, 184, 2068-2083. 


\section{Revised TOC art}

Manuscript ID: es-2016-03766u

Manuscript Type: Article

Author(s): Christie, Simon; Lobo, Prem; Lee, David; Raper, David

TOC art has been revised to comply with requested dimensions

$(8.4 \mathrm{~cm} \times 4.7 \mathrm{~cm})$

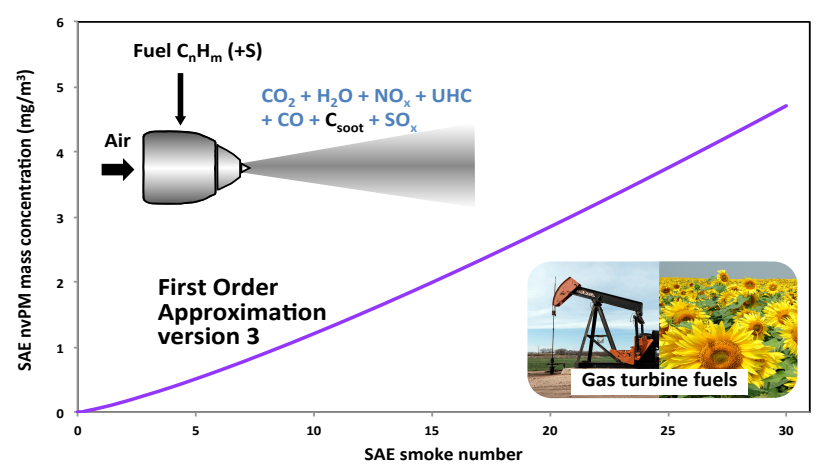

Source: TOC art is a composite made by the authors using powerpoint. The small images within the TOC art are licence free images that are publishable without restriction.

Pumpjack: https://www.loc.gov/item/2014631353/

Sunflowers: https://www.ars.usda.gov/plains-area/fargo-

nd/rrvarc/sun/docs/main/ 